\title{
Investigating schema therapy constructs in individuals with depression
}

\begin{abstract}
Background: Schema Therapy (ST) has been applied to several psychological disorders. The aim of this study was to further corroborate Renner's ST model for depression (2012), investigating maladaptive schemas, modes, and avoidant coping styles in a large non-clinical sample and in two sub-groups of subjects with high and low depression rates. Descriptive, correlation and multiple regression analyses were run on the whole sample and in the two sub-groups, with additional analyses comparing ST constructs in highly depressed versus not depressed individuals. Within the total sample, a positive correlation was observed between levels of depression and most maladaptive schemas, dysfunctional modes and intra-psychic avoidant coping strategies. Significant differences emerged with respect to the two sub-groups. Within the depressed group, positive associations occurred between the disconnection and rejection schema domain, the demanding parent mode and dissociative avoidant coping and symptoms severity. Multiple regression analyses also revealed the role of specific predictor variables explaining depression levels. Despite some important caveats, like the recruitment of a non-clinical sample, our data further support Renner's schema model for depression, adding some new evidences about the role of specific modes and avoidant coping strategies that seem to play a role in this psychopathological condition
\end{abstract}

Keywords: schema therapy, depression, early maladaptive schemas, modes, avoidant coping strategies
Volume 9 Issue 2 - 2018

\author{
Barbara Basile,' Katia Tenore,' Francesco \\ Mancini ${ }^{1,2}$ \\ 'Association of Cognitive Psychology (APC), School of \\ Cognitive Psychotherapy (SPC), Italy \\ ${ }^{2}$ Marconi University, Rome, Italy
}

Correspondence: Barbara Basile, Association of Cognitive Psychology (APC), School of Cognitive Psychotherapy (SPC), Rome, Italy,Viale Castro Pretorio I I 6, 00 I85, Rome, Italy, Tel +393476745487, Email basile_barbara@yahoo.it

Received: April 19, 20I8 | Published: April 25, 2018

\section{Introduction}

Schema Therapy ${ }^{1}$ is an integrated cognitive-behavioral approach, which combines traditional behavioral and cognitive strategies to experiential, emotion-focused and attachment models. It has been developed to treat personality disorders, as well as longstanding emotional difficulties that have their roots in childhood and adolescence. According to authors' theorization. ${ }^{1}$ Early Maladaptive Schemas (EMSs) are "pervasive themes, or patterns, of memories, bodily sensations, emotions and cognitions about oneself and relationships, developed during childhood/adolescence, when specific childhood needs are not met (i.e., safety, acceptance, love, rules \& limits, etc)". Young et al. ${ }^{1}$ recognized 18 schemas, determined by the interaction of child's temperamental features and specific experiences of unmet needs (see Table 1 for details about each schema). To deal with distress arising from schemas' activation, individuals develop specific copying strategies that represent their early survival strategies. Such coping styles, mutated from the well-known fight, flight and freeze responses, refer to overcompensation (i.e., attacking others, seeking for approval, etc.), avoidance (i.e., using strategies to avoid contact with needs and emotions, dissociation, behavioral avoidance, etc.) and surrender (i.e., submission toward abusive or neglecting relationships) strategies. The activation, in the here and now, of a specific maladaptive schema or coping strategy in a precise moment has been defined as "mode" (Table 2 for a detailed list of modes and their characteristics). One of the main goals of ST is to share with the patient his/her case conceptualization, usually in terms of modes, in order to get a deeper understanding of his/her functioning, and to help the client to strengthen his/her healthy adult mode, weakening dysfunctional coping modes and helping to fulfil core emotional needs. Specific ST mode models have been proposed and considered for several Axis I and II disorders, ${ }^{1-4}$ although less is known about the conceptualization of the ST mode model for depression. ${ }^{4}$ The aim of this study was to focus on Renner's model of depression, ${ }^{4,5}$ trying to identify early maladaptive schemas, modes and coping styles that characterize people suffering from depressive symptoms. The authors state that depression might be a result of distal risk factors (i.e., abuse, neglect, unmet needs in childhood), mediated by proximate risk factors (such as negative cognitive styles, interpersonal difficulties or general higher levels of psychopathology). Proximate risk factors are triggered by aversive current life events and are maintained by avoidant coping strategies and dysfunctional interpersonal behaviors (non-assertiveness, social isolation and so on). Social or conflicts' avoidance, in turn, contributes to depression maintenance. Overall, distal risk factors increase vulnerability towards proximate risk factors. For instance, abandonment or neglect from caregivers might foster the development of an abandonment schema and an actual trigger event, such as a loss, might activate the schema, and contribute to the development of depressive symptoms, especially if avoidant coping and interpersonal problems are present. ${ }^{6}$ The aim of this study was to further support Renner's model and to explore schemas, modes and avoidance coping styles in a large non clinical sample and in a sub-group of subjects characterized by high levels of depressive symptoms. Overall, we expect maladaptive schemas and dysfunctional modes' severity to be positively associated with higher depressive symptoms. Further, we hypothesize that schemas from the disconnection and rejection domain and the demanding parent mode would be more intense in depressed subjects, also predicting symptoms' severity. We also expect depressed individuals to favor more archaic avoidant coping strategies, as a consequence of earlier unmet core needs, typically associated to the disconnection and rejection schemas domain. 
Table I Description of the 15 early maladaptive schemas and their domains

\begin{tabular}{|c|c|}
\hline Early maladaptive schemas & Description \\
\hline \multicolumn{2}{|c|}{ Disconnection and rejection Domain } \\
\hline Emotional deprivation & The belief that others will never met the needs of emotional support \\
\hline Abandonment & The belief that others will be unavailable or unpredictable in their support and connection \\
\hline Mistrust/abuse & The belief that others will hurt, take advantage, abuse, and manipulate \\
\hline Social isolation & A feeling that one is isolated from the rest of the world and other people \\
\hline Defectiveness/shame & A feeling that one is defective, inferior or invalid \\
\hline \multicolumn{2}{|c|}{ Impaired autonomy and performance Domain } \\
\hline Failure & The belief that one has failed, or will fail in important life areas of achievement \\
\hline Dependence & The belief that one cannot afford everyday responsibilities without the help of others \\
\hline Vulnerability & Fear that inevitable catastrophic events will occur \\
\hline Enmeshment & $\begin{array}{l}\text { Being excessively emotionally involved/connected with important people, at the expense of full } \\
\text { individuation or normal social development }\end{array}$ \\
\hline \multicolumn{2}{|l|}{ Impaired limits Domain } \\
\hline Entitlement & The belief of being superior to other people, deserving special privileges \\
\hline Insufficient self-control & $\begin{array}{l}\text { Difficulty in self-control and distress tolerance or in restraining excessive emotional expression } \\
\text { or impulses }\end{array}$ \\
\hline \multicolumn{2}{|l|}{ Other directedness Domain } \\
\hline Subjugation & Always surrendering control to others due to the belief that one is coerced \\
\hline Self-sacrifice & The belief that one have to meet the needs of other people at the expense of oneself \\
\hline \multicolumn{2}{|c|}{ Over-vigilance and inhibition Domain } \\
\hline Emotional inhibition & An excessive inhibition of emotions, thoughts, and communications \\
\hline Unrelenting standards & $\begin{array}{l}\text { The belief that one must attain excessively high internalized standards of behaviour, usually to } \\
\text { avoid criticism }\end{array}$ \\
\hline
\end{tabular}

Table 2 Description of each mode, including the dysfunctional child, parental and coping modes, and the healthy adult mode

\begin{tabular}{|c|c|}
\hline Child modes & \\
\hline VulnerableChild & $\begin{array}{l}\text { Feels lonely, isolated, sad, misunderstood, unsupported, defective, deprived, overwhelmed, incompetent, unloved and } \\
\text { unlovable }\end{array}$ \\
\hline Impulsive/ & $\begin{array}{l}\text { Acts on non-core desires or impulses in a selfish or uncontrolled manner, unable to delay short-term gratification; feels } \\
\text { intensely angry, enraged, infuriated, frustrated, impatient }\end{array}$ \\
\hline \multicolumn{2}{|l|}{ Undisciplined Child } \\
\hline Happy Child & Feels loved, connected, satisfied, fulfilled, free, spontaneous \\
\hline \multicolumn{2}{|l|}{ Coping modes } \\
\hline Compliant Surrender: & $\begin{array}{l}\text { Acts in a passive, approval-seeking, tolerates abuse and/or bad treatment; does not express healthy needs or desires to } \\
\text { others }\end{array}$ \\
\hline Detached Protector: & Cuts off needs and feelings; detaches emotionally from people and rejects their help \\
\hline Over-compensator: & Feels and behaves in a very grandiose, aggressive, dominant, competitive, arrogant, over-controls \\
\hline \multicolumn{2}{|l|}{ Parent modes } \\
\hline Punitive Parent: & $\begin{array}{l}\text { Feels that oneself or others deserves punishment or blame and often acts on these feelings by being blaming, punishing, or } \\
\text { abusive towards self or others }\end{array}$ \\
\hline Demanding Parent: & Refer to the nature of the internalized high standards and strict rules \\
\hline \multicolumn{2}{|l|}{ Healthy adult mode } \\
\hline Healthy Adult: & $\begin{array}{l}\text { Performs appropriate adult functioning, such as working, parenting, taking responsibility, and committing and also practices } \\
\text { pleasure in a functional manner }\end{array}$ \\
\hline
\end{tabular}




\section{Methods}

\section{Participants}

Two-hundred-and-three US volunteers were recruited through an online survey (www.mturk.com). After providing instructions and informed consent, participants fulfilled several self-report measures in one single session. Measures were administered in a random order. All participants reported information about their age, gender, level of formal education, employment and marital status. Additional information about any on-going psychotherapy or drug treatment and eventual relatives' mental illness were collected. The study was conducted according to the Declaration of Helsinki guidelines (See, informed consent).

\section{Measures}

The following measures were administered, with Cronbach's alpha coefficient being calculated for each test. In a first analysis we included the whole sample, while further we selected only participants with a low and high depression profile. This was done to explore eventual differences in the schema/mode/coping styles profile within the two samples.

Centre for Epidemiological Studies-Depression Scale (CES-D): ${ }^{7}$ The CES-D is a 20-item self-report measure designed to measure depressive symptoms during the past week, in the general population. Total score ranges from 0 to 60 . Standard cut-offs are $>16$ for mild depression and $>23$ for clinical depression. Cronbach's alpha reliability coefficient was $\alpha=.80$, which implies acceptable internal consistency.

The Young Schema Questionnaire - Short form: The YSQ-SF ${ }^{8}$ is a 75-items questionnaire assessing 15 EMSs. Each scale consists of five items, and participants are asked to rate the items using a 6-point Likert scale (from $1=$ completely untrue of me, to $6=$ describes me perfectly). The 15 schemas included in the test are: Abandonment, Mistrust/Abuse, Emotional Deprivation, Defectiveness/shame, Social Isolation, Dependence, Vulnerability to Harm or Illness, Enmeshment/ undeveloped self, Failure, Entitlement, Insufficient Self-Control, Subjugation, Self-Sacrifice, Emotional inhibition and Unrelenting Standards. The YSQ-SF showed a high internal consistency, with a Cronbach's alpha coefficient $(\alpha)$ of .97 .

The Young - Rygh Avoidance Inventory (YRAI): ${ }^{9}$ contains 40 items that assess schema avoidance. Each item is rated on a 6 point Likert scale from 1 ("completely untrue of me") to 6 ("describes me perfectly"). The high rated items of this inventory represent the ways that patients used to avoid feeling the emotions which schemas engender. ${ }^{1}$ Although three different types of dysfunctional coping mechanisms have been identified, only schema avoidance was included because this coping strategy is hypothesized to be predominantly used in chronic depression. ${ }^{4}$ Usually, for research purposes, Young and other therapists divided YRAI items into 14 subscales, based on what they believe to be different avoidant strategies or symptoms, however, according to our aims and considering the weak reliability of this test, we extracted only three types of scores within the questionnaire, namely:

1. Intra-psychic (i.e., Denial of memories, Excessive rationality and control, etc.),

2. Behavioral (i.e., Substance abuse, Distraction through activity,
Avoidance of upsetting situations, etc.), and

3. Dissociative (i.e., Passive blocking of upsetting emotions, passive distraction through fantasy, day-dreaming or television) avoidance coping strategies. The internal consistency of the YRAI was quite acceptable, with $\alpha=.84$.

The Schema Mode Inventory (SMI): ${ }^{10}$ is a 124 self-descriptive statements that covers 14 modes (i.e., Vulnerable child, Angry child, Enraged child, Impulsive child, Undisciplined child, Happy child, Compliant child, Detached protector, Detached self-soother, Selfaggrandizer/Bully and attack mode, Punishing parent, Demanding parent, Healthy adult), where subjects have to rate the frequency on a 6-point scale ranging from "never or hardly ever" to "always"). The higher the score, the more frequent were the manifestations of the modes. Items of the SMI reflected emotions, cognitions or behaviours. Internal consistency coefficient was $\alpha=.96$, showing an excellent reliability.

\section{Data analysis}

Data were analysed using SPSS version 20.0 software (SPSS Inc., Chicago, IL). Overall, descriptive, correlation, t-tests to compare depressed versus not depressed participants, and multiple regression analyses were performed. In a first analysis we explored descriptive characteristics, correlations between levels of depression (CES-D total score) and schemas, modes and avoidant coping styles pervasiveness on the whole sample. Further, stepwise multiple regressions were performed to identify which variables among all schema constructs accounted for the amount of variance in depression. In a second phase, the same statistics, and an additional t-test analysis, were performed on the sub-groups of not-depressed and severely depressed subjects. According to participants' depression score on the CES-D, subjects scoring above the $75^{\text {th }}$ - and falling below the $25^{\text {th }}$ - percentile were selected in order to obtain two sub-groups. For each sample descriptive statistics were performed and schemas, modes and avoidant coping styles were compared across the two. Afterwards, within each group in isolation, correlation analyses and multiple regression analyses were calculated.

\section{Results}

\section{Descriptive statistics}

Demographic data on the whole sample, and in the not depressed and severely depressed groups are reported in Table 3 . The two subgroups did not differ in gender distribution, nor in their level of formal education and marital status, although depressed participants were significantly younger than not depressed. Levels of depression were very severe in the former group, with a mean score above 30 , where standard cut-off for clinical depression is above the score of 23. Conversely, individuals in the control group displayed a very low total score on the CES-D, far long away from 16, which is commonly used as overall cut-off. When considering subjects' eventual ongoing psychotherapy or drug treatment, no differences were detected between the two sub-groups. Although, severity of maternal mental impairment was significantly more frequent in the high depressed group ( $\mathrm{n}=17$ vs the not-depressed volunteers $\mathrm{n}=3$; Chi-Square, $\left.X^{2}(1)=13.74, \mathrm{p}=.000\right)$.

\section{Whole sample analyses}

Within the whole sample strong significant associations were 
detected between depressive symptoms severity and maladaptive schemas (strength of the associations ranging between .55 and .76, $\mathrm{p}<0.01$ ), dysfunctional modes (correlation indexes ranging between .41 and $.72, \mathrm{p}<0.01$ ) and avoidant coping strategies (correlation indexes range .73-.82, $\mathrm{p}<0.01)$. Multiple regression analyses were used to test if the schemas, modes and avoidant coping strategies significantly predicted participants' ratings of depression. In order to increase overview and interpretability, we performed the regression analyses for schema constructs separately. The results indicated that defectiveness/shame $(\beta=.30, \mathrm{p}<.000)$, entitlement $(\beta=.27, \mathrm{p}<.000)$, abandonment $(\beta=.28, p<.000)$, unrelenting standards $(\beta=.11, p<.03)$, emotional deprivation $(\beta=-.21, \mathrm{p}<.006)$ and the social isolation $(\beta=.16$, $\mathrm{p}<.02)$ schemas explained $58 \%$ of the variance $(\mathrm{F}(6,202)=46.42$, $\left.\mathrm{p}<.000, \mathrm{R}^{2}=.58\right)$. When considering modes as predictors, the vulnerable $(\beta=.48, \mathrm{p}<.000)$ and the impulsive $(\beta=.23, \mathrm{p}<.001)$ child, the demanding parent $(\beta=.28, \mathrm{p}<.000)$ and the compliant surrender coping $(\beta=-.17, \mathrm{p}<.01)$ modes explained $54 \%$ of depression severity $\left(\mathrm{F}(4,202)=59.48, \quad \mathrm{p}<.000, \quad \mathrm{R}^{2}=.54\right)$. Finally, intra-psychic and dissociative coping mechanisms together $(\beta=.74, \mathrm{p}<.000)$ accounted for $55 \%$ of depression ratings $\left(\mathrm{F}(1,202)=254, \mathrm{p}<.000, \mathrm{R}^{2}=.55\right)$.

\section{Between groups' comparisons}

In order to compare the two sub-groups, t-independent sample tests were performed to detect for eventual differences in schemas, modes and coping strategies between not-depressed and severely depressed subjects. Overall, the former group reported significantly more pervasive maladaptive schemas, dysfunctional modes and avoidant coping strategies (See table 4 for mean scores, standard deviations and statistical significance), compared against not depressed subjects. Further, partial correlations to explore the association between depression severity and ST related constructs were run, controlling for age and maternal mental impairment (Table 5 for statistical significances). Most of maladaptive schemas and dysfunctional modes were positively correlated to symptoms' severity in the depressed group alone, whereas within the control group few statistically significant associations were detected, probably also because of a pavement effect. In detail, depression rates within the not depressed subjects was positively correlated with the entitlement and the unrelenting standards schemas, and the happy child and the healthy adult modes, and negative associations were observed with the detached protector mode, and the vulnerable and impulsive child modes. Within the depressed group, the strongest correlations with depression index was found with the abandonment and mistrust/abuse schemas, the detached protector, the demanding parent and the angry/ enraged child modes, and with the dissociation coping strategy. Next, we performed multiple regression analysis in which schema therapy constructs were regressed on the depression index, in each sub-group in isolation. Again, in order to increase overview and interpretability, also considering reduced sample size, we performed the regression analyses for schemas, modes and coping strategies separately. Within the highly depressed sample, the abandonment $(\beta=.45, p<.001)$, unrelenting standards $(\beta=.36, \mathrm{p}<.001)$, entitlement $(\beta=.39, \mathrm{p}<.003)$ and subjugation $(\beta=-.39, p<.003)$ schemas explained $55 \%$ of variance $\left(\mathrm{F}(4,46)=14,05, \mathrm{p}<.000, \mathrm{R}^{2}=.55\right)$. Whereas against modes, the demanding parent mode $(\beta=.49, \mathrm{p}<.000)$ alone accounted for $24 \%$ of depression severity $\left(\mathrm{F}(1,49)=15,457, \mathrm{p}<.000, \mathrm{R}^{2}=.24\right)$. The coping style that best explained $40 \%$ of depression rates $(F(1,50)=29,92$, $\left.\mathrm{p}<.000, \mathrm{R}^{2}=.40\right)$ was dissociation $(\beta=.61, \mathrm{p}<.000)$. When running regression models in the not depressed group (where the range of CES-D score was between 0 and 13), the only maladaptive schema explaining for levels of depression $\left(\mathrm{F}(1,56)=16.53, \mathrm{p}<.000, \mathrm{R}^{2}=.23\right)$ was the unrelenting standards schema $(\beta=.48, \mathrm{p}<.000)$, while, across modes, the impulsive child $(\beta=-.61, \mathrm{p}<.000)$ and the punitive parent $(\beta=.42, p<.001)$ accounted for $32 \%$ of variance $(F(2,56)=18,84$, $\mathrm{p}<.000, \mathrm{R}^{2}=.32$ ). Again, as in the depressed sub-group, dissociation $(\beta=.51, \mathrm{p}<.000)$ alone explained ratings of depression $(\mathrm{F}(2,56)=19,33$, $\mathrm{p}<.000, \mathrm{R}^{2}=.26$ ).

Table 3 Demographic data on the whole sample, and the no- and high-depression groups are reported. T-tests were performed to detect between groups' differences in levels of depression (see last column for levels of significance). Abbreviations: CES-D, Centre for Epidemiological Studies - Depression Scale). P value of significance according to Chi-Squares and t-tests referring to the two sub-groups are reported. ns= not significant difference

\begin{tabular}{lllll}
\hline & Whole sample $\mathbf{N = 2 0 3}$ & $\begin{array}{l}\text { Not depressed sample } \\
\mathbf{N = 5 7}\end{array}$ & $\begin{array}{l}\text { Highly-depressed } \\
\text { sample N=5 I }\end{array}$ & P value \\
\hline CES-D total Mean score [SD] & $19.9[8.5]$ & $10.6[2.7]$ & $31.6[9.7]$ & 0 \\
Mean age [SD] years & $36.9[13.6]$ & $40.1[13.9]$ & $31.2[9.7]$ & 0 \\
Gender \% & $63 \%$ female & $61 \%$ female & $64 \%$ female & $\mathrm{ns}$ \\
Level of formal education \% & $31 \%$ bachelor & $35 \%$ bachelor & $31 \%$ college & ns \\
& $27 \%$ college & $26 \%$ college & $27 \%$ bachelor & ns \\
Marital status (single / married) \% & $43 \%$ single & $42 \%$ single & $56 \%$ single & $25 \%$ married \\
\hline
\end{tabular}

Table 4 Means and Standard Deviations for maladaptive schemas, modes and avoidant coping strategies are shown. Two-sample t test significant differences across groups for $\mathrm{p}<0.001$. *Difference between sub-groups was not significant. Abbreviations: $\mathrm{SD}=$ standard deviation; $\mathrm{CS}=\mathrm{coping}$ styles

\begin{tabular}{|c|c|c|c|c|c|}
\hline \multirow{2}{*}{ Maladaptive Schemas } & \multicolumn{2}{|l|}{ Mean SD } & \multirow{2}{*}{ Modes } & \multicolumn{2}{|l|}{ Mean SD } \\
\hline & No depres & High depres & & No depres & High depres \\
\hline \multirow{2}{*}{ Emotional deprivation } & 1.72 & 3.321 .18 & Vulnerable child & 1.72 & 3.5 \\
\hline & 1 & & & 0.71 & 0.9 \\
\hline \multirow{2}{*}{ Abandonment } & 1.48 & 3.37 & Enraged child & 2 & 2.76 \\
\hline & 0.75 & 1.86 & & 0.35 & 0.84 \\
\hline \multirow{2}{*}{ Abuse/mistrust } & 1.67 & 3.54 & Angry child & 1.96 & 2.91 \\
\hline & 0.92 & 1.23 & & 0.39 & 0.8 \\
\hline
\end{tabular}


Table Continued

\begin{tabular}{|c|c|c|c|c|c|}
\hline \multirow{2}{*}{ Maladaptive Schemas } & \multicolumn{2}{|l|}{ Mean SD } & \multirow{2}{*}{ Modes } & \multicolumn{2}{|l|}{ Mean SD } \\
\hline & No depres & High depres & & No depres & High depres \\
\hline \multirow{2}{*}{ Social isolation } & 1.8 & 3.69 & Impulsive child & 1.54 & 2.98 \\
\hline & 0.98 & 1.11 & & 0.55 & 0.98 \\
\hline \multirow{2}{*}{ Defectiveness/shame } & 1.36 & 3.31 & $\begin{array}{l}\text { Undisciplined } \\
\text { child }\end{array}$ & 1.81 & 2.98 \\
\hline & 0.76 & 1.14 & & 0.57 & 0.94 \\
\hline \multirow{2}{*}{ Failure } & 1.64 & 3.17 & Happy child & 4.11 & 3.55 \\
\hline & 0.9 & 1.35 & & 0.87 & 0.89 \\
\hline \multirow[t]{2}{*}{ Dependency } & 1.57 & 3 & $\begin{array}{l}\text { Compliant } \\
\text { surrender coping } \\
\text { mode }\end{array}$ & 2.44 & 3.42 \\
\hline & 0.84 & 1.23 & & 0.71 & 0.85 \\
\hline \multirow[t]{2}{*}{ Vulnerability to harm } & 1.62 & 3.25 & $\begin{array}{l}\text { Detached } \\
\text { protector coping } \\
\text { mode }\end{array}$ & 1.55 & 3.05 \\
\hline & 0.79 & 1.08 & & 0.62 & 0.93 \\
\hline \multirow[t]{2}{*}{ Enmeshment/undeveloped self } & 1.37 & 2.66 & $\begin{array}{l}\text { Detached self- } \\
\text { soother coping } \\
\text { mode }\end{array}$ & 2.97 & 3.42 \\
\hline & 0.61 & 1.13 & & 0.6 & 0.6 \\
\hline \multirow[t]{2}{*}{ Entitlement/grandiosity } & 1.64 & 3.05 & $\begin{array}{l}\text { Self-aggrandizer } \\
\text { coping mode }\end{array}$ & 1.7 & 2.85 \\
\hline & 0.57 & 0.93 & & 0.53 & 0.87 \\
\hline \multirow[t]{2}{*}{ Insufficient self-control } & 1.64 & 3.28 & $\begin{array}{l}\text { Bully/attack } \\
\text { coping mode }\end{array}$ & 1.54 & 2.56 \\
\hline & 0.79 & 1.01 & & 0.5 & 0.98 \\
\hline \multirow{2}{*}{ Self-sacrifice } & $2.92^{*}$ & $3.43 *$ & $\begin{array}{l}\text { Punitive/critical } \\
\text { Parent }\end{array}$ & 2.4 & 3.15 \\
\hline & 1.46 & 0.94 & & 0.4 & 0.73 \\
\hline \multirow{2}{*}{ Subjugation } & 1.67 & 3.02 & $\begin{array}{l}\text { Demanding } \\
\text { Parent }\end{array}$ & 2.29 & 3.28 \\
\hline & 0.83 & 0.99 & & 0.51 & 0.62 \\
\hline \multirow{2}{*}{ Emotional inhibition } & 1.76 & 3.32 & Healthy adult & $3.37^{*}$ & $3.39 *$ \\
\hline & 0.86 & 1.01 & & 0.64 & 0.64 \\
\hline \multirow{2}{*}{ Unrelenting standards } & 2.71 & 3.72 & & & \\
\hline & 0.91 & 0.94 & & & \\
\hline \multicolumn{6}{|l|}{ Coping styles } \\
\hline \multirow[t]{2}{*}{ Intra-psychic avoidance CS } & 1.5 & 3.26 & $\begin{array}{l}\text { Dissociation } \\
\text { avoidance CS }\end{array}$ & 2.18 & 3.38 \\
\hline & 0.63 & 0.81 & & 0.63 & 0.83 \\
\hline \multirow{2}{*}{ Behavioral avoidance CS } & 2.11 & 3.84 & & & \\
\hline & 0.75 & 0.84 & & & \\
\hline
\end{tabular}


Table 5 Pearson correlation analyses between depression severity and early maladaptive schemas, modes and coping strategies, considering each sub-group (i.e., not-depressed and depressed) in isolation. Abbreviations: CES-D,Centre for Epidemiological Studies - Depression Scale, n.s.= not significant

\begin{tabular}{|c|c|c|c|c|c|}
\hline \multirow{2}{*}{ Schemas } & \multicolumn{2}{|l|}{ CES-D } & \multirow{2}{*}{ Modes } & \multicolumn{2}{|l|}{ CES-D } \\
\hline & No & High & & No & High \\
\hline \multirow{2}{*}{ Emotional deprivation } & 0.008 & 0.384 & \multirow{2}{*}{ Bully attack } & -0.29 & 0.29 \\
\hline & n.s. & 0.003 & & n.s. & 0.02 \\
\hline \multirow{2}{*}{ Abandonment } & 0.049 & 0.494 & \multirow{2}{*}{ Angry Child } & -0.075 & 0.452 \\
\hline & n.s. & 0 & & .n.s. & 0.001 \\
\hline \multirow{2}{*}{ Mistrust/abuse } & 0.091 & 0.447 & \multirow{2}{*}{ Happy Child } & 0.365 & 0.241 \\
\hline & n.s. & 0.001 & & 0.003 & 0.04 \\
\hline \multirow{2}{*}{ Social isolation } & 0.075 & 0.257 & \multirow{2}{*}{ Compliant surrender } & -0.044 & 0.214 \\
\hline & n.s. & 0.03 & & n.s. & n.s. \\
\hline \multirow{2}{*}{ Defectiveness } & -0.082 & 0.248 & \multirow{2}{*}{ Detached Protector } & -0.305 & 0.392 \\
\hline & n.s. & 0.04 & & 0.01 & 0.003 \\
\hline \multirow{2}{*}{ Failure } & 0.066 & 0.194 & \multirow{2}{*}{ Demanding parent } & 0.048 & 0.445 \\
\hline & n.s. & n.s. & & n.s. & 0.001 \\
\hline \multirow{2}{*}{ Dependence } & 0.036 & 0.191 & \multirow{2}{*}{ Detached Self Shooter } & 0.132 & 0.286 \\
\hline & n.s. & n.s. & & n.s. & 0.02 \\
\hline \multirow{2}{*}{ Vulnerability } & 0.11 & 0.299 & \multirow{2}{*}{ Enraged Child } & -0.187 & 0.424 \\
\hline & n.s. & 0.01 & & n.s. & 0.001 \\
\hline \multirow{2}{*}{ Enmeshment } & 0.132 & -0.025 & \multirow{2}{*}{ Healthy Adult } & 0.368 & 0.431 \\
\hline & n.s. & n.s. & & 0.003 & 0.001 \\
\hline \multirow{2}{*}{ Entitlement } & 0.334 & 0.326 & \multirow{2}{*}{ Impulsive Child } & -0.416 & 0.388 \\
\hline & 0.007 & 0.01 & & 0.001 & 0.003 \\
\hline \multirow{2}{*}{ Insufficient self-control } & 0.144 & 0.441 & \multirow{2}{*}{ Punitive Parent } & 0.17 & 0.307 \\
\hline & n.s. & 0.002 & & n.s. & 0.01 \\
\hline \multirow{2}{*}{ Subjugation } & 0.082 & 0.158 & \multirow{2}{*}{ Self Aggrandizer } & -0.09 & 0.372 \\
\hline & n.s. & n.s. & & n.s. & 0.004 \\
\hline Self_cacrifice & 0.179 & 0.286 & Indiscinlined Child & -0.091 & 0.304 \\
\hline & n.s. & 0.02 & & n.s. & 0.01 \\
\hline Emotional inhibition & 0.104 & 0.187 & Vulnomblo Child & -0.295 & 0.32 \\
\hline Emotional inhibition & n.s. & n.s. & vulnerable Child & 0.01 & 0.01 \\
\hline Unerlonting sandarde & 0.466 & 0.358 & & & \\
\hline Ginrelening staniuar us & 0 & 0.006 & & & \\
\hline Coping strategies & No & High & Coping strategies & No & High \\
\hline Intmoncher & 0.054 & 0.361 & Dissociation & 0.5 & 0.559 \\
\hline III apsycric & n.s. & 0.005 & & 0 & 0 \\
\hline & 0.16 & 0.337 & Intrapsychic + Dissociation & 0.243 & 0.465 \\
\hline Denavioural & n.s. & 0.009 & & 0.03 & 0 \\
\hline
\end{tabular}

\section{Discussion}

In this study we investigated levels of depression, early maladaptive schemas, avoidant coping styles and modes in individuals recruited from a normal population. Our aim was to further support Renner's schema model and to identify specific ST related constructs that might characterize depressive symptoms. Overall, as expected, we found a positive association between rates of depression and dysfunctional schemas and modes pervasiveness. Further, specific analyses were run to explore eventual differences between depressed and not-depressed sub-groups of subjects. Overall, schemas, dysfunctional modes and avoidant coping strategies pervasiveness was higher in depressed (vs not-depressed) individuals, with strong associations with symptoms' severity, in the whole sample of subjects and specifically in the depressed sub-group. Additionally, depression rates were explained by specific maladaptive schemas, and by the demanding parent mode and the intra-psychic and dissociative coping strategies. According to Renner's model, the abandonment schema represents an important proximate risk factor in the development of depression. People displaying this schema expect that significant others will leave them, not providing them with the emotional support they need, and not giving an adequate protection. In most of the cases people with this 
schema have experienced significant and mostly unpredictable losses in their early life. ${ }^{11}$ Many studies found that early trauma, including abuse and neglect/emotional deprivation, predicts depressive symptoms in adulthood, ${ }^{12-15}$ while other authors revealed that childhood trauma might predict depression directly, ${ }^{16-18}$ and indirectly through maladaptive schemas ${ }^{19}$ or experiential avoidance. ${ }^{20}$ Moreover, other schemas within the disconnection and rejection schema-domain (i.e., defectiveness/shame, emotional deprivation and social isolation) predicted levels of depression severity within the total sample and in the depressed sub-group alone. In another study including a nonclinical Iranian women sample ${ }^{21}$ authors showed that disconnection and rejection schemas mediate between childhood trauma and depressive symptoms. The vulnerable child mode, another explaining variable of depression rates in our total sample, embodies those feelings of loneliness, isolation, unlikableness and defectiveness that are associated with disconnection and rejection schemas and might get triggered in specific situations. Another maladaptive schema that was found to predict levels of depression was subjugation, referring to those surrender and submissive beliefs that might activate behaviorally trough the corresponding compliant surrender coping mode. When this mode is activated the individual complies with other people's wishes and suppresses own needs and desires. In a clinical sample with mainly depressive symptoms it has been shown that schemas from the disconnection and rejection domain (specifically abandonment and defectiveness/shame), but unexpectedly not the subjugation and failure schemas, were cross-sectionally related to depression severity. ${ }^{22}$ Another schema associated with depression was the unrelenting standards one. This includes the belief that one must strive to meet very high standards, usually to avoid criticism or punishments, at the expenses of any moment of playfulness or positive emotion. Together with its corresponding demanding parent mode, both variables explained depression gravity, in the whole sample as well as in the depressed sub-sample alone. The demanding parent mode represents the internalization of parental messages pressuring the child to achieve unrealistically high expectations. When high standards are not met, intense disappointment, sufferance and selfcriticism might arise. Self-criticism is commonly implicated in the development and maintenance of depression, and represents an important risk factor for this disorder. ${ }^{23}$ As a consequence of this pressure to achieve, the depressed individual might react surrendering control to others in order to avoid anger, retaliation or even abandonment. Despite the critical role of the unrelenting standards, unexpectedly, we did not find a significant association between depression levels and the failure schema, where the individual beliefs that one has failed, or will do, in important life areas of achievement. Finally, within the depressed participant's sample, the entitlement accounted for depression rates. This schema refers to a sense of superiority and grandiosity, with the belief that one has special rights and privileges, and is not bound by the rules of reciprocity that guide normal social interaction. The predicting power of the entitlement schema on depression rates might seem quite surprising; however it might also represent a form of overcompensation for feelings of defectiveness and shame, and for the emotional deprivation and social exclusion familiarities. ${ }^{11}$ Finally in line with Renner's model we investigated the role of avoidant coping in depressive symptoms. Avoidance is a common coping strategy in depression. ${ }^{4,24}$ We found that the type of avoidant coping style that best predicted depressive symptoms were dissociation, and, overall, intra-psychic avoidant coping strategies. Dissociative avoidance is the most archaic and instinctive coping strategy to deal with sufferance and psychological pain. Other intra-psychic strategies involve mental acts such as passive blocking of upsetting emotions, fantasy, daydreaming, denial of memories, and excessive rationality. Renner considers avoidance as the most typical survivor strategy in depression. Our data confirm his model, additionally suggesting that mental, more than behavioral (i.e., substance use, active distraction trough activity) avoidance strategies play a main role in depression. Other studies investigated the role of ST constructs in predicting therapy outcome. In one study Renner et al. ${ }^{25}$ found that schemas within the over vigilance \& inhibition domain (i.e., unrelenting standards, emotional inhibition) at pre-treatment were negatively related to symptoms' severity at posttreatment. Other studies investigated the efficacy of ST approach on chronic depression or depressive episodes. In one single case series study, ${ }^{26}$ the five schema domains, together with symptoms reduction, showed a significant decrease after 50 sessions of ST intervention. More in detail, the change from baseline to post-treatment was large and highly significant for the domains of disconnection \& rejection, impaired autonomy and performance and over-vigilance and inhibition In a last study ${ }^{27}$ dysphoric symptoms were predicted by failure, pessimism, emotional deprivation, vulnerability to harm or illness and entitlement schemas. Despite the important contribution of these studies, however, eventual changes in specific schemas, modes or dysfunctional coping strategies had not been measured. Limitations of this study provide pathways for additional research. First, although participants within the high-depression group reported clinically significant scores on the CES-D, they were selected from a normal population. Drawing conclusion and generalizing our findings to clinical depression or chronic depression might be too risky. Further, due to the cross- sectional nature of this study, it is not possible to make causal inferences on associations or predictive models. As well, other confounding factors, and other not detected variables, might have affected the relationship between ST related variables and depression. For instance, our depressed participants reported significantly more frequent maternal mental impairment. Previous studies reported that maternal psychopathological condition, for instance depression, is related with child internalizing problems. Compared to children of never-depressed mothers, children exposed to maternal depression prior to the age of 10 have been found to be twice as likely to develop major depression or dysthymic disorder ${ }^{28}$ and anxiety disorders. ${ }^{29-38}$

\section{Conclusion}

This study showed that specific early maladaptive schemas, modes and avoidant coping strategies characterize depressed subjects. Renner's Schema Therapy model for depression was partially replicated, adding some important peculiarities related to the role of the demanding parent mode and the dissociative avoidant coping style. Future work involving clinical populations and more psychological and interpersonal variables should be addressed in the future.

\section{Funding}

The present work was funded by the School of Cognitive Psychotherapy, cuola di Psicoterapia Cognitiva S.r.l. (SPC), Rome, Italy.

\section{Conflict of interest}

Authors declare that there is no conflict of interest. 


\section{References}

1. Young JE, Klosko J, Weishaar ME. Schema therapy: A practitioner's guide. New York, NY: Guilford Press; 2003.

2. Gross EN, Stelzer N, Jacob G. Treating OCD with the Schema Mode Model. In: Michiel van Vreeswijk, Jenny Broersen, Marjon Nadort, editors. The Wiley-Blackwell Handbook of Schema Therapy: Theory, Research, and Practice. John Wiley \& Sons, Ltd; 2012.

3. Arntz A. Schema Therapy for Cluster-C Personality Disorders. In: Michiel van Vreeswijk, Jenny Broersen, Marjon Nadort, editors, The Wiley-Blacllwell Handbook, of Schema Therapy: Theory, Hesearch, and Practice. John Wiky \& Sons, Ltd. 2012.

4. Renner F, Arntz A, Leeuw I. Treatment for chronic depression using schema therapy. Clinical Psychology: Science and Practice. 2013;20(2):166-180.

5. Arntz A. Schema Therapy in Practice: An Introductory Guide to the Schema Mode Approach. Wiley Blackwel. 2013.

6. Klein DN, Santiago NJ. Dysthymia and chronic depression: introduction, classification, risk factors, and course. Journal of Clinical Psychology. 2003;59(8):807-16.

7. Radloff LS. The CES-D scale: A self-report depression scale for research in the general population. Applied Psychological Measurements. 1977;1(3):385-401.

8. Young JE. Young Schema Questionnaire Short Form. 1st ed. New York: Cognitive Therapy Center; 1998

9. Young JE, Young Rygh. Avoidance Inventory (YRAI); 1994.

10. Young JE, Arntz A, Atkinson T, et al. The Schema Mode Inventory. New York: Schema Therapy Institute; 2007.

11. Warburton W, McIlwain D. The Role of Early Maladaptive Schema in Adult Aggression. Psychology, Psychiatry, and Mental Health Monographs. The Journal of the NSW Institute of Psychiatry. 2005;2:17-34.

12. Schulz A, Becker M, Auwera SVD, et al. The impact of childhood trauma on depression: does resilience matter? Population-based results from the study of health in Pomerania. Journal of Psychosomatic Research. 2014;77(2):97-103

13. Suzukia A, Poonc L, Papadopoulos AS. Long term effects of childhood trauma on cortisol stress reactivity in adulthood and relationship to the occurrence of depression. Psychoneuroendocrinology. 2014;50:289-299.

14. Agorastos A, Pittman JOE, Angkaw AC, et al. The cumulative effect of different childhood trauma types on self-reported symptoms of adult male depression and PTSD, substance abuse and health-related quality of life in a large active-duty military cohort. J Psychiatr Res. 2014;58:46-54.

15. Pompili M, Innamorati M, Lamis DA, et al. The associations among childhood maltreatment, "male depression" and suicide risk in psychiatric patients. Psychiatry Research. 2014;220(1-2):571-578.

16. Kounou KB, Bui E, Dassa KS, et al. Childhood trauma, personality disorders symptoms and current major depressive disorder in Togo. Soc Psychiatry Psychiatr Epidemiol. 2013;48(7):1095-1103.

17. Michopoulos V, Powers AL, Moore C, et al. The mediating role of emotion dysregulation and depression on the relationship between childhood trauma exposure and emotional eating. Appetite. 2015;91:129-136.

18. Miron LR, Orcutt HK. Pathways from childhood abuse to prospective revictimization: depression, sex to reduce negative affect, and forecasted sexual behavior. Child Abuse Negl. 2014;38(11):1848-1859.

19. Calvete F, Orue I, Hankin BL. Transactional relationships among cognitive vulnerabilities, stressors, and depressive symptoms in adolescence. $J$ Abnorm Child Psychol. 2013;41(3):399-410.
20. Bell KM, Higgins L. The impact of childhood emotional abuse and experiential avoidance on maladaptive problem solving and intimate partner violence. Behav Sci. 2015;5(2):154-175.

21. Rezaei M, Ghazanfari F, Rezaee F. The role of childhood trauma, early maladaptive schemas, emotional schemas and experimental avoidance on depression: A structural equation modeling. Psychiatry Research. 2016;246:407-414.

22. Petrocelli JV. Cognitive schemas as mediating variables of the relationship between the self-defeating personality and depression. Journal of Psychopathology and Behavioral Assessment. 2001;23(3):183-191.

23. Blatt SJ, Zuroff DC. Interpersonal relatedness and self- definition: Two prototypes for depression. Clinical Psychology Review. 1992;12(5):527562.

24. Carvalho JP, Hopko DR. Behavioral theory of depression: Reinforcement as a mediating variable between avoidance and depression. J Behav Ther Exp Psychiatry. 2011;42(2):154-162.

25. Renner F, Lobbestael J, Peeters F, et al. Early maladaptive schemas in depressed patients: Stability and relation with depressive symptoms over the course of treatment. J Affect Disord. 2012;136(3):581-90.

26. Malogiannis IA, Arntz A, Spyropoulou A, et al. Schema therapy for patients with chronic depression: a single case series study. J Behav Ther Exp Psychiatry. 2014;45(3):319-29.

27. Trincas R, Ottaviani C, Couyoumdjian A, et al. Specific Dysphoric Symptoms Are Predicted by Early Maladaptive Schemas. The scientific world journal. 2014;8:1-7.

28. Hammen CL, Brennan PA. Severity, chronicity, and timing of maternal depression and risk for adolescent offspring diagnoses in a community sample. Arch Gen Psychiatry. 2003;60(3):253-258.

29. Gelfand DM, Teti DM. The effects of maternal depression on children. Clinical Psychology Review. 1990;106:329-353.

30. Alloy LB, Abramson LY, Whitehouse WG. Prospective incidence of first onsets and recurrences of depression in individuals at high and low cognitive risk for depression. J Abnorm Psychol. 2006;115(1):145-156.

31. Burcusa SL, Iacono WG. Risk for recurrence in depression. Clinical Psychology Review. 2007;27(8):959-985.

32. Carter JD, McIntosh VV, Jordan J, et al. Psychotherapy for depression: a randomized clinical trial comparing schema therapy and cognitive behavior therapy. J Affect Disord. 2013;151(2):500-505.

33. Renner F, Arntz A, Peeters FP, et al. Schema therapy for chronic depression: Results of a multiple single case series. J Behav Ther Exp Psychiatry. 2016;51:66-73.

34. Riso LP, Froman SE, Raouf M, et al. The long-term stability of early maladaptive schemas. Cognitive Therapy and Research. 2012;30(4):515529

35. Schatzman SM. Early maladaptive schemas mediating the relationship between perceptions of early parenting and depression and anxiety. Theses and Dissertations. 2009.

36. Skodol AE, Grilo CM, Keyes KM, et al. Relationship of personality disorders to the course of major depressive disorder in a nationally representative sample. American Journal of Psychiatry. 2011;168(3):257264.

37. Sowislo JF, Orth U. Does low self-esteem predict depression and anxiety? A meta-analysis of longitudinal studies. Psychol Bull. 2013;139(1):213-40.

38. Young JE. Young Compensation Inventory (YCI-1); 2003. 